Arq. Bras. Med. Vet. Zootec., v.68, n.1, p.147-154, 2016

\title{
Caracterização de colágenos tipos I e III no estroma do carcinoma de células escamosas cutâneo em cães
}

\author{
[Characterization of types I and III collagen in the stroma of cutaneous \\ squamous cell carcinoma in dogs] \\ S.A.O. Bedoya ${ }^{1}$, L.G. Conceição ${ }^{1}$, M.I.V. Viloria ${ }^{1}$, F.H. Loures $^{1}$, F.L. Valente ${ }^{1}$, \\ R.L. Amorim ${ }^{2}$, F.F. Silva ${ }^{3}$ \\ ${ }^{1}$ Universidade Federal de Viçosa - Viçosa, MG \\ ${ }^{2}$ Faculdade de Medicina Veterinária e Zootecnia - Unesp - Botucatu, SP \\ ${ }^{3}$ Universidade Federal de Viçosa - Viçosa, MG
}

\begin{abstract}
RESUMO
O carcinoma de células escamosas (CCE) é uma neoplasia epitelial maligna que acomete cães e diversas outras espécies, incluindo a humana. O CCE afeta vários sítios anatômicos e pode desenvolver metástase. O objetivo deste estudo foi a caracterização das fibras de colágenos tipos I e III no estroma do CCE cutâneo de cães. Para este trabalho, utilizaram-se 44 amostras de pele incluídas em parafina e que tiveram prévio diagnóstico de CCE. As amostras foram processadas histologicamente e coradas com hematoxilina/eosina para confirmação do diagnóstico e classificação do grau de diferenciação tumoral e com a coloração histoquímica de picrosirius para observação dos colágenos tipos I e III. O colágeno tipo III mostrou maior expressão nos CCEs cutâneos bem diferenciados. O papel do colágeno do tipo III nas neoplasias não está bem esclarecido, e outros fatores além do grau de diferenciação celular podem estar envolvidos em sua expressão e determinar sua importância na biologia tumoral.
\end{abstract}

Palavras-chave: neoplasia epitelial, pele, hematoxilina eosina, picrosirius

\begin{abstract}
Squamous cell carcinoma (SCC) is a malignant epithelial tumor that affects dogs and several other species, including humans. The SCC occurs in various anatomical sites and can develop metastasis. The aim of this study was to characterize types I and III collagen fibers in the stroma of cutaneous SCC in dogs. For this work 44 paraffin-embedded samples with previous diagnostic of SCC were used. Samples were processed and evaluated histologically with hematoxylin/eosin to confirm the diagnosis and classification of cell differentiation degree and with Picrosirius for observation of types I and III collagen. Type III collagen expression was higher in well-differentiated SCC. The role of type III collagen in cancer is not very clear and factors other than cell differentiation degree may be involved in its expression and determine its importance in tumor biology.
\end{abstract}

Keywords: epithelial neoplasm, skin, hematoxylin/eosin, picrosirius

\section{INTRODUÇ̃̃̃O}

A matriz extracelular (MEC) é principalmente composta por duas classes de macromoléculas: proteínas fibrosas (incluindo colágenos e elastina) e glicoproteínas (incluindo fibronectina, proteoglicanos e laminina) (Mouw et al., 2014). O colágeno é a proteína mais comum no reino

Recebido em 31 de maio de 2015

Aceito em 16 de setembro de 2015

E-mail: adriana.ortiz.bedoya@gmail.com animal, constituindo o arcabouço extracelular para todos os organismos multicelulares, e desempenha importantes funções estruturais e morfogênicas em matrizes e membranas basais em muitos tecidos e órgãos (Iwasaki et al., 2012). Na derme, o colágeno é um componente importante e desempenha um papel-chave na resistência e elasticidade da pele (Verhaegen et al., 2012). As fibras colágenas representam $90 \%$ 
de todas as fibras dérmicas e $80 \%$ da matriz extracelular dérmica. Os colágenos tipos I, III e $\mathrm{V}$ são os que predominam na derme, sendo responsáveis por aproximadamente $87 \%, 10 \%$ e $3 \%$, respectivamente, do colágeno dérmico (Miller et al., 2013).

A MEC está em constante remodelação e sua síntese e degradação acompanha a morfogênese, a regeneração, a cura de feridas e os processos fibróticos crônicos (Kumar et al., 2010). Estudos recentes na medicina humana têm mostrado que as interações das células tumorais com 0 microambiente tecidual, especialmente com as proteínas da MEC, sugerem que a MEC desempenha um papel fundamental no desenvolvimento e na progressão do tumor (Koening et al., 2006; Lin e Yun, 2010). As fibras de colágeno tipo I são o principal componente estrutural do estroma em diversos tumores e a sua presença reduz a adesão celular e contribui para a progressão do câncer (Koening et al., 2006; Li et al., 2010). Provenzano et al. (2008) sugerem que uma alta densidade de fibras colágenas tipo I aumenta significativamente a iniciação, a progressão e a metástase do tumor. Este tipo de colágeno pode ser considerado como um biomarcador potencial em câncer de mama com metástase para o pulmão (Kakkad et al., 2012).

Picrosirius é uma coloração seletiva de tecido conjuntivo (Sweat et al., 1964) que permite uma análise qualitativa das fibras colágenas do tecido conjuntivo. Quando observada sob luz polarizada, pela diferença na interferência de cores, na intensidade e na birrefringência dos tecidos corados, essa coloração permite a diferenciação principalmente das fibras tipo I e tipo III (Sweat et al., 1964; Montes, 1996).

O principal uso da coloração do picrosirius é na coloração e diferenciação dos diferentes tipos de colágeno (Weatherford, 1972), porém ela também tem sido utilizada para o diagnóstico diferencial de neoplasias fibrocísticas (Koren et al., 2001). Na medicina veterinária, não há relatos de quantificação dos colágenos tipos I e III por meio desta técnica para o carcinoma de células escamosas (CCE) cutâneo em caninos. Portanto, este trabalho tem como objetivo caracterizar as fibras de colágenos tipos I e III no estroma de CCE cutâneo em cães, segundo o grau de diferenciação neoplásica.

\section{MATERIAL E MÉTODOS}

Foram utilizadas 44 amostras de pele canina, incluídas em parafina (blocos de parafina), provenientes do Laboratório de Histopatologia da Universidade Federal de Viçosa (UFV) e do Laboratório Provet-SP, com diagnóstico histopatológico de carcinoma de células escamosas cutâneo. Não existiu restrição de sexo, raça ou faixa etária para a seleção e conformação dos grupos. Este estudo foi realizado após a aprovação do projeto de pesquisa pela Comissão de Ética para Uso de Animais da UFV (protocolo $\mathrm{n}^{\circ} 78 / 2014$ ).

Os blocos de parafina foram cortados com espessura de $5 \mu \mathrm{m}$, corados com hematoxilina/ eosina (HE) para avaliação histopatológica e com a coloração histoquímica picrosirius para observação de fibras de colágeno (tipos I e III), respectivamente.

Os cortes histológicos corados com HE foram observados em microscópio óptico de luz para confirmar o diagnóstico e definir o grau de diferenciação tumoral. Os tumores foram classificados, de acordo com suas características histológicas, em bem diferenciado ou pouco diferenciado (Ramos et al., 2007; Cardona et al., 2013). O critério histológico foi o seguinte:

bem diferenciado: o tumor é semelhante ao epitélio escamoso, com progressão ordenada de células basais poliédricas não queratinizadas na periferia, as quais estão dispostas em cordões compactos ou ninhos de tamanhos variados, com abundante tecido conjuntivo e grande quantidade de queratina, o que determina a formação de pérolas de queratina lameladas no centro das ilhas;

pouco diferenciado: existem células imaturas com numerosas mitoses, com ausência de ninhos de células e mínima quantidade de queratina sem a formação das pérolas.

Todos os cortes foram corados com picrosirius e examinados ao microscópio óptico sob luz polarizada (Olympus BX-53 §, Japão). A observação das fibras colágenas por meio desse método permitiu a diferenciação do colágeno tipo I (birrefringência laranja- amarelado a laranja e vermelha) e tipo III (birrefringência verde ou verde-amarela) (Coleman, 2011). De 
cada lâmina, foram selecionados e fotomicrografados 10 campos histológicos com câmera digital $(5.0 \mathrm{~m})$ no aumento de $40 x$. Os campos foram selecionados da esquerda para a direita e de cima para baixo e, para cada campo fotomicrografado, dois campos eram desprezados, até que fosse obtido o total de 10 campos. As imagens foram analisadas com ajuda do software Image J, com o plug-in Threshold Colour, obtendo-se o percentual de colágeno por meio da análise de partículas automatizadas de acordo com seleção e medida das áreas com base na cor. Os valores para cada tipo de colágeno no Threshold Colour foram padronizados para todas as imagens do seguinte modo: matiz $0-40$ para a cor vermelha (colágeno tipo I) e 45-120 para a cor verde (colágeno tipo III), saturação 0-255 e brilho 5-225 para ambos os tipos de colágeno (Fig. 1). Algumas amostras foram avaliadas por planimetria por contagem de pontos para se verificar a precisão da análise automática.
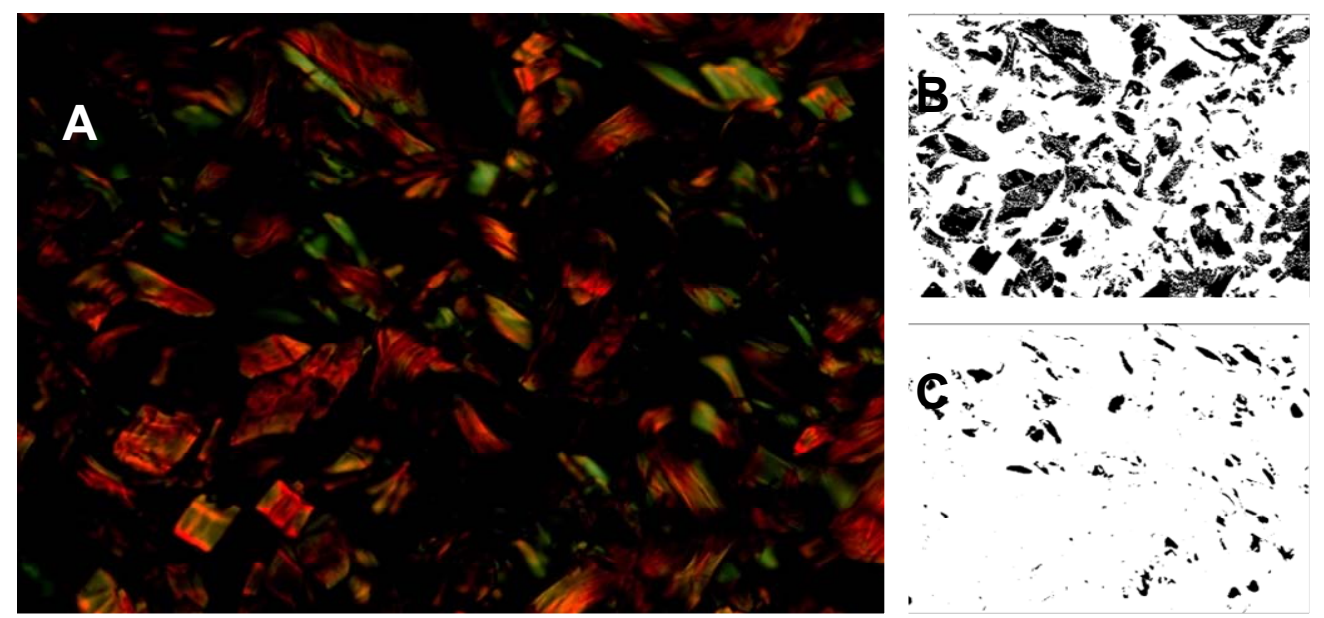

Figura 1. Fotomicrografia de pele normal mostrando a área de colágenos tipos I e III, medida com o software Image J usando o plug-in Threshold Colour. A) Imagem original observada com luz polarizada. B) A cor preta corresponde à área selecionada para medida de colágeno tipo I pelo software. C) Área selecionada para medida do colágeno tipo III.

A raça, o sexo e a idade dos animais acometidos foram identificados e, por sua frequência, descritos. As porcentagens dos diferentes tipos de colágeno segundo o grau de diferenciação foram comparadas pelo teste $\mathrm{t}$ de Student ou pelo Mann-Whitney, respectivamente, se atendessem ou não à pressuposição de normalidade. As análises foram realizadas pelo software SigmaPlot 11.0, considerando-se o nível de 5\% de significância para todos os testes adotados.

\section{RESULTADOS}

Dos 44 casos com diagnóstico de CCE cutâneo que ingressaram no estudo, 36\% eram de cães sem raça definida (SRD) (16 casos), 30\% da raça Pit Bull (13 casos), 7\% Boxer (três casos), 5\% Poodle (dois casos), e a minoria de casos ocorreu nas raças Pastor Canadense, Bull Terrier, Lhasa Apso, Dachshund, Dálmata, Dogue, Cocker e
Fila Brasileiro, com um caso cada, o que representou $2 \%$ cada. Dois casos não forneceram informação sobre a raça, representando $5 \%$ das amostras. Quanto ao sexo, observou-se que as fêmeas eram maioria, com 61\% (27 casos), e o os machos representaram $34 \%$ dos casos (15 casos). Dois casos não tinham a informação sobre o sexo, o que representou $5 \%$ das amostras. A idade variou de quatro a 14 anos, com uma média de oito anos. As lesões encontraram-se distribuídas principalmente no tronco, correspondente a $43,18 \%$ do total dos casos (19 casos), $20,45 \%$ em cabeça (nove casos) e $18,18 \%$ em membros (oito casos). Oito casos não forneceram informação sobre local do tumor, representando $18,18 \%$ das amostras.

A análise histológica das lesões mostrou que $77 \%$ eram bem diferenciados (34 casos), e 23\% pouco diferenciados (10 casos) (Fig. 2 e 3 ). 


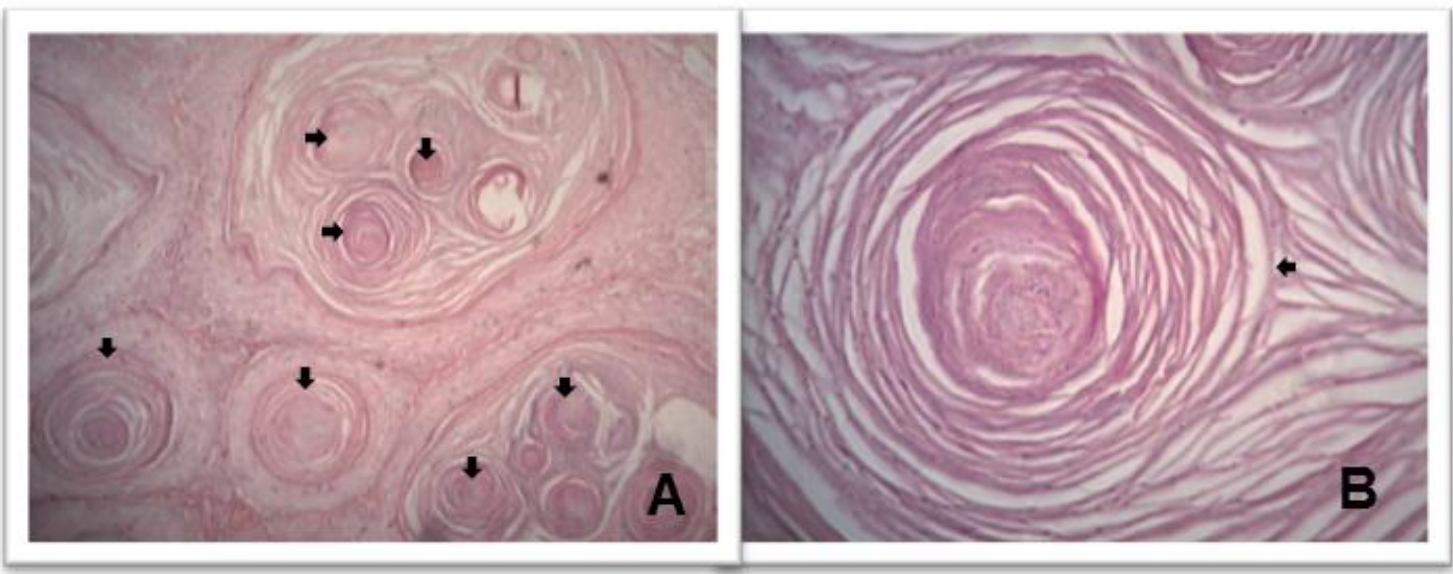

Figura 2. Carcinoma de células escamosas cutâneo bem diferenciado em cão. A) Notar as pérolas de queratina em abundância (setas pretas). HE, 10x. B) Destaque de uma pérola de queratina (seta preta). HE, 40x.

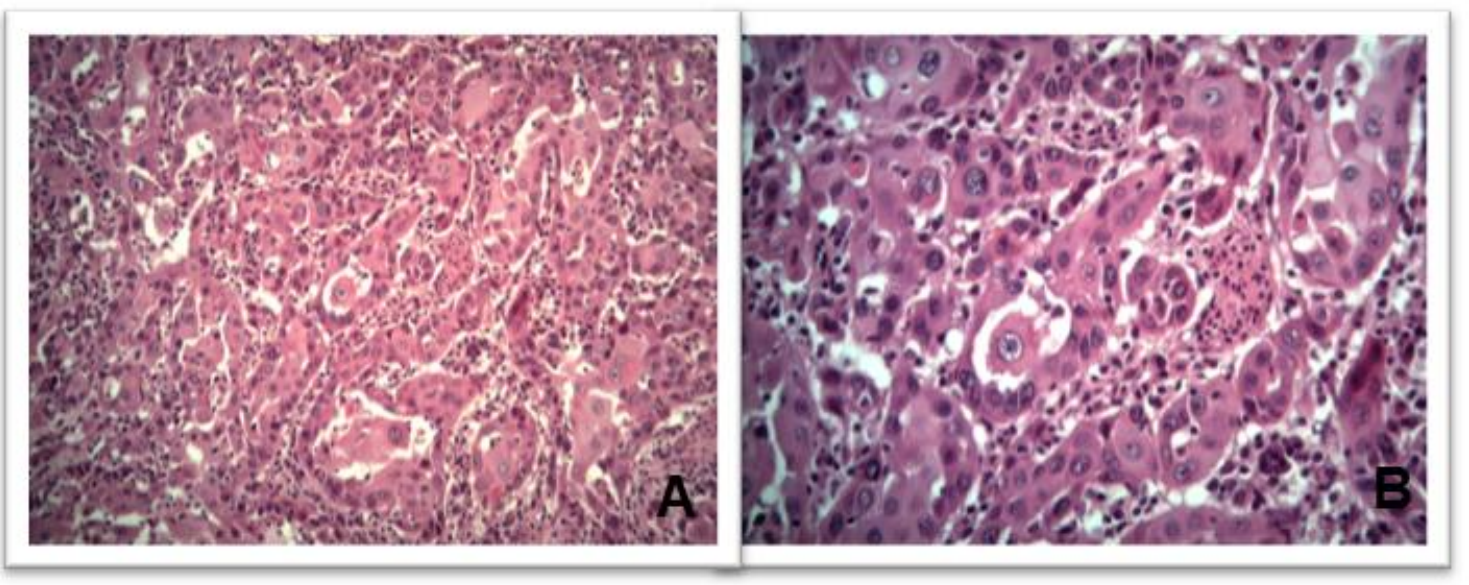

Figura 3. Carcinoma de células escamosas cutâneo pouco diferenciado em cão. A) Observa-se anaplasia, pleomorfismo e produção de queratina notavelmente reduzida, HE, 20x. B) Destaque da lâmina A. HE, 40x.

A coloração de picrosirius sob luz polarizada permitiu a visualização do colágeno tipo I mostrando marcada birrefringência laranja e vermelha. Percebeu-se que as fibras colágenas do tipo I eram dominantes, estavam distribuídas irregularmente e dispostas como grandes bandas de diferentes comprimentos que separavam os cordões compactos ou ninhos, os quais, com frequência, rodeavam parcial ou descontinuamente a área neoplásica. Havia desorganização e fragmentação acentuada das fibras colágenas do tipo I nos diferentes graus de diferenciação tumoral, sendo menos marcada nos CCEs bem diferenciados (Fig. 4 e 5). As fibras colágenas tipo III distribuíram-se por áreas escassas de birrefringência verde-amarelada e verde nos diferentes graus de diferenciação tumoral. Foram observadas em pouca quantidade, com tamanhos e formas variadas distribuídas no estroma neoplásico (Fig. 5).

A análise dos dados revelou que não houve diferença estatística entre a expressão de colágeno do tipo I de acordo com a diferenciação tumoral $(\mathrm{P}=0,708)$. Entretanto, o colágeno do tipo III ocorreu em maior quantidade nos carcinomas bem diferenciados $(\mathrm{P}=0,037)$ (Fig. 6). 


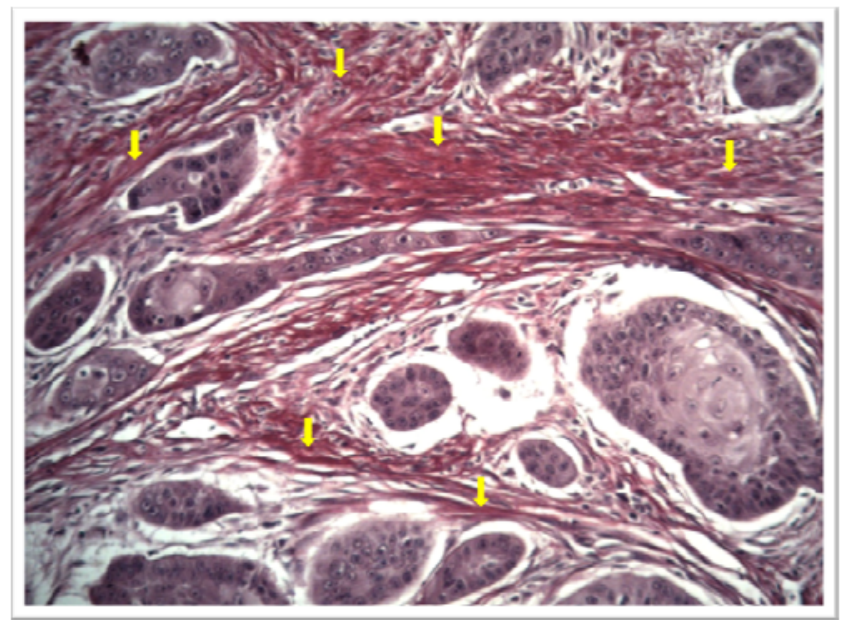

Figura 4. Picrosirius sem polarização. Mostram-se as fibras colágenas rodeando as células tumorais (setas) 20x.

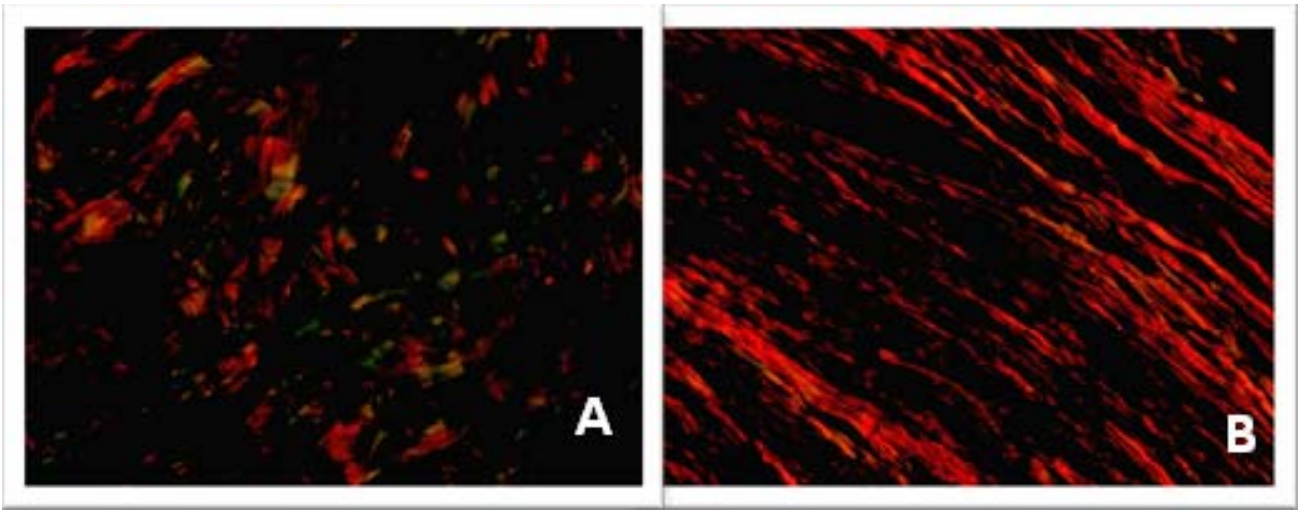

Figura 5. Fibras colágenas tipo I (cor vermelha) e III (cor verde) com picrosirius com polarização. A) CCE cutâneo bem diferenciado, com presença de fibras colágenas tipo I e tipo III. B) Pouco diferenciado, com predomínio de colágeno tipo I. PR/P, 40x.

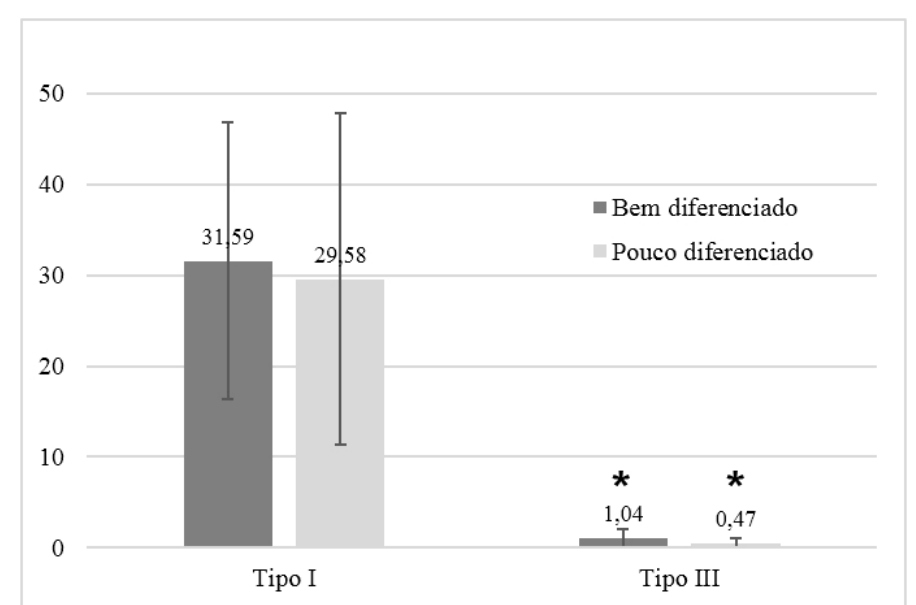

Figura 6. Representação gráfica das médias e dos desvios-padrão da porcentagem de colágenos dos tipos I e III segundo o grau de diferenciação das amostras. Os asteriscos indicam os pares que apresentaram diferença estatística ( $\mathrm{t}$ de Student para colágeno tipo I e Mann-Whitney para tipo III, $\alpha=5 \%$ ). 


\section{DISCUSSÃO}

O colágeno nos tecidos representa uma barreira física contra a invasão tumoral, e sua arquitetura sofre importantes alterações nos tumores (Egeblad et al., 2010). Após a iniciação do tumor, muitas das fibras colágenas tornam-se mais espessas progressivamente e linearizam-se. Tal linearização é mais notável nas áreas adjacentes à vasculatura do tumor e nas áreas com células cancerígenas (Provenzano et al., 2006). Essa reestruturação física do colágeno intersticial endurece progressivamente a MEC, o que provoca diversos efeitos sobre a diferenciação celular, a expressão gênica, a proliferação, sobrevivência e migração das células cancerígenas (Egeblad et al., 2010).

A proteólise da MEC é fortemente controlada em tecidos normais, mas tipicamente desregulada em tumores. A degradação do colágeno por proteases, incluindo catepsinas e metaloproteinases (MMPs), é importante para a invasão da célula cancerígena, gerando vias para que as células migrem pela MEC. A clivagem do colágeno do tipo I por MMP1, $-8,-13$ e -14 (MT1-MMP) resulta na geração de fragmentos que possuem cerca de $1 / 4 \mathrm{e}^{3 / 4}$ do comprimento da molécula colagênica nativa. Esses fragmentos podem atuar como antagonistas de colágeno com comprimento normal porque se ligam à integrina $\alpha 2 \beta 1$, mas não conseguem ativá-la. No entanto, tais fragmentos podem promover a migração e a sobrevivência celular, ativando a integrina $\alpha \mathrm{v} \beta 3$ (Egeblad et al., 2010).

$\mathrm{Na}$ análise das fibras colágenas do estroma de CCE cutâneo de cães com o método $\mathrm{PR} / \mathrm{P}$, observou-se que havia fragmentação acentuada $\mathrm{e}$ desorganização das fibras colágenas, especialmente do tipo I, nos diferentes graus de diferenciação tumoral, sendo menos marcada nos CCEs bem diferenciados. A desorganização das fibras colágenas observada neste estudo coincide com os resultados obtidos no estudo realizado por Martins et al. (2002) em neoplasias mamárias benignas e malignas em cães, nas quais as fibras colágenas encontravam-se distribuídas irregularmente no estroma de carcinomas e de uma forma mais ordenada e regular nos tumores benignos.

$\mathrm{Na}$ pele normal, os colágenos tipo I e tipo III predominam na derme, representando $87 \%$ e
$10 \%$ do colágeno dérmico, respectivamente (Miller et al., 2013). Neste estudo, o colágeno predominante foi o tipo I, em todos os graus de diferenciação tumoral. No entanto, não foi encontrada diferença estatística na quantidade de colágeno tipo I.

Em diversos estudos, o colágeno tipo I mostrou que é o componente estrutural mais abundante em tumores sólidos e altamente expresso em tumores invasivos e metastáticos (Cheng e Leung, 2011). Esse tipo de colágeno produz-se amplamente no estroma de carcinoma de pâncreas, próstata, ovário e estômago em humanos (Koening et al., 2006; Docheva et al., 2010; Li et al., 2010, Cheng e Leung, 2011). Sua presença reduz a adesão celular e aumenta a proliferação tumoral, a migração celular e a invasão (Koening et al., 2006; Cheng e Leung, 2011).

Encontrou-se que o colágeno tipo III se expressa em maior quantidade nos CCEs cutâneos bem diferenciados em comparação aos CCEs pouco diferenciados. Esses resultados mostram similaridade com um estudo realizado por Samar et al. (2012), em glândulas salivares de humanos, onde foi observado o predomínio do colágeno tipo I em tumores malignos e de colágeno tipo III em tumores benignos. Ainda que o CCE cutâneo bem diferenciado não seja uma neoplasia benigna, o prognóstico é muito melhor quando comparado com um CCE de menor grau de diferenciação histológica, o qual apresenta maior probabilidade de recidivas, ocorrência de metástases e pior prognóstico (Rodaski e Werner, 2009; Yanofsky et al., 2011). No entanto, Cardona et al. (2013) encontraram presença moderada de colágeno maduro tipo I e ausência do tipo III em CCE cutâneo bem diferenciado em bovinos. Estes mesmos autores sugeriram que isto poderia indicar a escassa resposta regenerativa do organismo ante $o$ processo de progressão das células cancerígenas.

Fuentes et al. (2012) realizaram um estudo para determinar as mudanças progressivas na lâmina basal e a remodelação do tecido conjuntivo durante a carcinogênese induzida com 4nitroquinolina-1-óxido (4NQO) em ratos. Esses autores observaram uma destruição progressiva da membrana basal e desorganização do colágeno tipo I no tecido conjuntivo, assim como evidentes mudanças na composição do colágeno. 
Nesse estudo, o colágeno tipo I estava diminuído e foi substituído por fibras colágenas finas tipo III em displasia de alto grau e CCE oral. De modo semelhante, Allon et al. (2006), em seu estudo sobre diferenças estromais em tumores de glândula salivar, encontraram que $50 \%$ das fibras de colágeno em adenocarcinoma polimorfo de baixo grau e carcinoma adenoide cístico era colágeno tipo III, enquanto no adenoma pleomórfico (neoplasia benigna) apenas 13\% era colágeno tipo III. Os autores sugeriram que as fibras colágenas estavam ligeiramente comprimidas em tumores salivares mais agressivos, constituídos provavelmente por colágeno III, intermédio ou colágeno patológico, o que facilitaria a invasão a tecidos adjacentes e o desenvolvimento de metástases. Essas alterações na composição das fibras de colágeno representam uma grande desorganização do esqueleto básico da MEC. Os resultados desses estudos diferem dos encontrados no presente trabalho, já que a proporção de colágeno tipo I foi predominante em todos os graus de diferenciação tumoral e o colágeno tipo III vai diminuindo à medida que se perde o grau de diferenciação tumoral.

O papel do colágeno tipo III nas neoplasias não está bem esclarecido. Existem outros fatores que podem ser empregados na determinação do grau de malignidade de uma neoplasia, além do grau de diferenciação, e que poderiam também influenciar na expressão de colágeno, de forma que estudos adicionais podem ser necessários com um número maior de amostras para inclusão de outras variáveis, as quais permitam obter resultados mais conclusivos que contribuam no diagnóstico, prognóstico e tratamento.

\section{CONCLUSÃO}

Alterações da composição e distribuição das fibras colágenas no estroma de CCE cutâneo em cães foram evidenciadas com a coloração picrosirius. Houve predomínio do colágeno tipo I nos diferentes graus de diferenciação tumoral, porém não houve diferença na expressão desse tipo de colágeno entre os graus. Os resultados deste estudo mostraram que há maior expressão de colágeno tipo III nos CCEs cutâneos bem diferenciados que nos CCEs cutâneos poucos diferenciados.

\section{AGRADECIMENTOS}

Os autores agradecem a CAPES, FAPEMIG e CNPq.

\section{REFERÊNCIAS}

ALLON, I.; VERED, M.; BUCHNER A.; DAYAN, D. Stromal differences in salivary glands tumors of a common histopathogenesis but with different biological behavior. Acta Histochem., v.108, p.259-264, 2006.

CARDONA, J.A.; VARGAS, M.I.; PERDOMO, S.C. Estudio clínico e histopatológico del carcinoma de células escamosas de bovinos en el departamento de Córdoba, Colombia. Rev. Fac. Cienc. Vet.. UCV., v.54, p.68-77, 2013.

CHENG, J.C.; LEUNG, P.C. Type I collagen down-regulates E-cadherin expression by increasing PI3KCA in cancer cells. Cancer Lett., v.304, p.107-233, 2011.

COLEMAN, R. Picrosirius red staining revisited. Acta Histochem., v.113, p.231-233, 2011.

DOCHEVA, D.; PADULA, D.; SCHIEKER, M.; CLAUSEN-SCHAUMANN $H$. Effect of collagen I and fibronectin on the adhesion, elasticity and cytoskeletal organization of prostate cancer cells. Biochem. Biophys. Res. Commun., v.402, p.361-366, 2010.

EGEBLAD, M.; RASCH, M.G.; WEAVER, VM. Dynamic interplay between the collagen scaffold and tumor evolution. Curr. Opin. Cell. Biol., v.22, p.697-706, 2010.

FUENTES, B.; DUASO, J.; DROGUETT, D. et al. Progressive extracellular matrix disorganization in chemically induced murine oral squamous cell carcinoma. ISRN Pathol., v.2012, p.1-7, 2012.

IWASAKI, S; YOSHIZAWA, H; AOYAGI, H. Localization of type III collagen in the lingual mucosa of rats during the morphogenesis of circumvallate papillae. Odontology, v.100, p.1021, 2012.

KAKKAD, S.M.; SOLAIYAPPAN, M.; ARGANI, P. et al. Collagen I fiber density increases in lymph node positive breast cancers: pilot study. J. Biomed. Opt., v.17, p.1-7, 2012. 
KOENING, A.; MUELLER, C.; HASEL, C. et al. Collagen type I induces disruption of ecadherin- mediated cell-cell contacts and promotes proliferation of pancreatic carcinoma cells. Cancer. Res., v.66, p.4662-4671, 2006.

KOREN, R.; YANIV, E.; KRISTT D. et al. Capsular collagen staining of follicular thyroid neoplasms by picrosirius red: Role in differential diagnosis. Acta Histochem., v.103, p.151-7, 2001.

KUMAR, V.; ABBAS, A.K; FAUSTO, N.; ASTER, J.C. Renovação, regeneração e reparo dos tecidos. In: KUMAR, V.; ABBAS, A.K; FAUSTO, N. et al. Patologia bases patológicas das doenças. Rio de Janeiro: Elsevier, 2010. p.79-110.

LI, A.; ZHOU, T.; GUO, L.; SI, J. Collagen type I regulates $\beta$-catenin tyrosine phosphorylation and nuclear translocation to promote migration and proliferation of gastric carcinoma cells. Oncol. Rep., v.23, p.1247-1255, 2010.

LIN, Q.; YUN, Z. Impact of the hypoxic tumor microenvironment on the regulation of cancer stem cell characteristics. Cancer Biol. Ther., v.9, p.949-956, 2010.

MARTINS, A.M.C.R.P.F.; TAMASO, E.; GUERRA, J.L. Histochemical study of fibrillar proteins of the extracellular matrix in benign and malignant mammary neoplasms in dogs. Braz. $J$. Vet. Res. An. Sci., v.39, p.43-49, 2002.

MILLER, W.H.; GRIFFIN, C. E.; CAMPBELL, K.L. Muller and Kirk's small animal dermatology. 7.ed. St. Louis: Elsevier, 2013. p.774-843.

MONTES, G.S. Structural biology of the fibres of the collagenous and elastic systems. Cell Biol. Int., v,20, p.15-27, 1996.

MOUW, J.K.; OU G.; WEAVER, V. M. Extracellular matrix assembly: a multiscale deconstruction. Mol. Cell. Biol., v.15, p.771-785, 2014.
PROVENZANO, P.P.; ELICEIRI, K.W.; CAMPBELL, J.M. et al. Collagen reorganization at the tumor-stromal interface facilitates local invasion. BMC Med., v.4, p.1-16, 2006.

PROVENZANO, P.P.; INMAN, D.R.; ELICEIRI, K.W. et al. Collagen density promotes mammary tumor initiation and progression BMC Med., v.6, p.1-15, 2008.

RAMOS, A.; NORT, D.; ELIASI, F.; FERNANDES, C. Carcinoma de células escamosas em bovinos, ovinos e equinos: estudo de 50 casos no sul do Rio Grande do Sul. Braz. J. Vet. Res. An. Sci., v.44, p.5-13, 2007.

RODASKI, S.; WERNER, J. Neoplasias de pele. In: DALECK, C.R.; NARDI, A.B; RODASKI. Oncologia em cães e gatos. São Paulo: Roca, 2009. p.254-297.

SAMAR, M.E.; VILA, R.E.; ASIS, O.G. et al. Identificación de colágeno I y III con picrosirius red/ polarización en el estroma de tumores salivares. Int. J. Odontostomat., v.6, p.59-64, 2012.

SWEAT, F.; PUCHTLER, H.; ROSENTHAL, SI. Sirius red F3BA as a stain for connective tissue. Arch. Pathol. Lab. Med., v.78, p.69-72, 1964.

VERHAEGEN, P.D.; SCHOUTEN, H.J.; TIGCHELAAR-GUTTER; W. et al. Adaptation of the dermal collagen structure of human skin and scar tissue in response to stretch: an experimental study. Wound Repair Regen., v.20, p.658-666, 2012.

WEATHERFORD, T.W. Staining of collagenous and non-collagen structures with picrosirius red F3BA. J. Med. Sci., v.9, p.383-388, 1972.

YANOFSKY, V.R.; MERCER, S.E.; PHELPS, R.G. Histopathological variants of cutaneous squamous cell carcinoma: a review. J. Skin Cancer., v.2011, p.1-13, 2011. 